\title{
Patient Satisfaction Measurement by MedRisk Instrument
}

\author{
Élcio Alves Guimarães', Mariana Nunes Faria², Kennedy Rodrigues Lima², Kelly Duarte Lima Makhoul², \\ Lucas Resende Sousa ${ }^{4}$, Paulo Cézar Simamoto Junior ${ }^{5}$, Gilmar da Cunha Sousa ${ }^{6}$, Alfredo Júlio Fernandes Neto ${ }^{5}$
}

\begin{abstract}
Background: The importance of evaluating the user's perspective when dealing with the quality of health services has been a constant and the user's role as protagonist of this system has a direct impact on improving service. Thus, it is essential to know how users evaluate the care provided to rethink professional practices or intervene in the form of organization of services, to its improvement. Objectives: Assess the degree of patient satisfaction through MedRisk Instrument and identify the item that has the greatest impact on overall satisfaction. Methods/Design: The users of a university clinic of physical therapy, in rheumatology and pediatrics sectors, were asked about their degree of satisfaction, using MedRisk instrument. Results: Forty-six users completed the questionnaire. The $2 \mathrm{global}$ measures means were 4,86 and 4,86 in rheumatology sector; and 4,76 and 4,84 in pediatrics sector. The specific items that had higher level of satisfaction and the highest correlation with overall satisfaction were items $6,7,8$ and 11 . Conclusion: The university physiotherapy clinic was assessed with a high degree of satisfaction to its users and items related to the therapist-patient interaction have more influence on overall satisfaction. Thus demonstrating that the MedRisk instrument is effective, functional and wide applicability.
\end{abstract}

Key Words: Measurement Instrument, Quality in Health, Physical Therapy Satisfaction

\section{INTRODUCTION}

The Western world is experiencing a post-industrial, service-based economy, and the increasing participation of the industry in the world economy leads us to the analysis of the appropriate levels of excellence and quality of the services provided. There is a huge diversity of service types, and in all of them it is imperative to understand and manage quality, aiming the loyal and satisfied customers ${ }^{(1)}$.

The quality of the care still continues to generate great concern in health, but the main focus of the research has been mainly the technical quality of the clinical specialties, and little aspects of patient satisfaction ${ }^{(2)}$. However, user's satisfaction has been considered increasingly important for health services, as it is seen as an indicator of the quality of care offered, and its evaluation is fundamental when seeking improvements in care. Assessing patient satisfaction is therefore a necessary step when aiming to achieve quality in health care ${ }^{(3)}$.

Satisfaction is the expression of an attitude, that is, an affective response that is related to the belief that the service must have adequate component and dimension. Thus, it is defined as positive evaluations of the individual about different dimensions of the service and it is established according to the expectations of the client. It is seen as a subjective assessment ${ }^{(4)}$.
Among the determinants of satisfaction that are often mentioned are the professional conduct (technical competence, communication), accessibility, convenience, costs and the physical structure ${ }^{(5)}$.

Therefore, measuring the quality of services is a challenge. The satisfaction of the users of the health service is multidimensional in nature, that is, the individual may be satisfied with one or more aspects of a service and / or consultation and simultaneously be dissatisfied with others service dimensions. In this way, the degree of satisfaction achieved reflects a set of factors that go beyond the eminently clinical scope, through dimensions such as the structure of the environment, the service rendering process (care) and results obtained with the treatment ${ }^{(6)}$.

Physiotherapy has characteristics that can influence patient satisfaction. Physiotherapeutic care often requires much more time than a routine clinical visit, as it usually involves physical contact, requiring active patient participation ${ }^{(7)}$. Therefore, they are factors that can alter satisfaction indexes ${ }^{(3)}$.

The patient's satisfaction significance is further emphasized by the evidence that satisfied patients are more likely to adhere to treatment and achieve better quality of life ${ }^{(8)}$. This fact is justified by the physiotherapist establishing a relationship with

\footnotetext{
Corresponding Author: Élcio Alves Guimarães Address: Av Dos Vinhedos, 900 - Bairro Morada da Colina Uberlândia - Minas Gerais - Brazil CEP 38411 -159 Telephone: +55 34 99687-4951 E-mail: elcio@unitri.edu.br

1. Physiotherapist, doctor in Odontology, Faculty of Odontology, Universidade Federal de Uberlândia (UFU), Uberlândia - Minas Gerais - Brazil.

Full list of author information is available at the end of the article
}

Financial Support: There was no financial support.

Submission date 20 June 2017; Acceptance date 10 September 2017; Publication date 06 October 2017 
the patient revealing interest in his improvement, clarifying his doubts and explaining what was done in the treatment. Thus, a therapist-patient relationship of trust and safety is established, motivating the patient during treatment to achieve improvement in their pain ${ }^{(9)}$.

One study demonstrated that commitment between patient and therapist correlates positively with treatment outcomes in physical rehabilitation programs, including: ability to perform daily life activities, pain, specific physical functional tasks, depression, global assessment of physical health, adherence to treatment and satisfaction with treatment ${ }^{(10)}$.

In the pedagogical clinics connected to higher education institutions, where the attendance is carried out by students who are in the last year of undergraduate training under the supervision of Physiotherapy professors with, at least, a specialist title depending of the institution. Thus, the patient-therapist relationship presents special characteristics, since the patients attended at the clinic-schools undergo the treatment performed by academics ${ }^{(3)}$.

University education influences the future professional attitude of academics, which will affect the personal life of the student and the lives of other people. The supervised internship complements the student's formation with practical training in real situations, presents an educator-trainer character and also allows the provision of services to the community, aiming to train the professional physiotherapist in its totality, respecting the ethical and disciplinary basis of the profession and seeking to develop critical subjects so that higher education is not a process dissociated from social reality. These practices require evaluations, interventions and reflections of the physiotherapeutic processes. In addition, in the case of a school clinic, indirectly these surveys also allow us to collect information about the quality of teaching offered to students ${ }^{(11)}$.

In the field of health care, patient's satisfaction is usually measured through questionnaires. These instruments are used to indicate the quality of therapeutic care as well as to identify patients who are more likely to adhere to treatment programs ${ }^{(12)}$. Therefore, an instrument for assessing patient satisfaction for medical visits would not be adequate for physiotherapy, configuring the need to use a specific instrument ${ }^{(7)}$.

In view of the above, it was intended with this work to apply the MedRisk Instrument as a form of evaluation, in order to verify the degree of satisfaction of the users regarding the quality of the physiotherapy service of the clinical center of the "Centro Universitário do Triângulo".

\section{METHODOLOGY}

This was an empirical research applied in the field, with descriptive objective and quantitative approach, approved by the Ethics Committee of the Centro Universitário do Triângulo (Protocol number 1402 415) and the participants signed the
Free and Informed Consent Form. Each subject was informed that personal data would be published and that their identity would be kept protected.

The research was carried out in the clinic-school of Physiotherapy of the Centro Universitário do Triângulo, located in Uberlândia, Minas Gerais, Brazil, from March to April 2016. All the users, over 18 years of age or those responsible for patients under 18 years of age, of the rheumatology and pediatrics sectors of the School Clinic participated in the study in the first half of 2016. Users who declined or were unable to respond to the questionnaire and patients who had undergone fewer than five sessions of physical therapy were not included in the survey.

The data were collected by direct documentation, using the Medrisk - Instrument Questionnaire for Measuring Patient Satisfaction with Physical Therapy Care (MRPS). It was delivered to each user, who carried out the filling without intervention of the researcher.

MedRisk is a tool developed in English language in the United States specifically to measure satisfaction in patients who have received physiotherapy care ${ }^{(13)}$.

In 2007, the instrument was validated in Spanish for US residents of Hispanic origin who do not speak English could be subject to search without the need for interpreters and without invasion of their privacy, and the results showed its effectiveness also in that language. This instrument had the advantage of being succinct and easy to graduate, and provided measurements with evidence of reliability and validity ${ }^{(14)}$.

Since then, an international collaboration of researchers, supported by the World Confederation of Physiotherapy, has conducted a series of studies aimed at developing versions of the MRPS questionnaire in different languages (German, Mandarin, Arabic, Norwegian, Korean, Indonesian and Brazilian Portuguese). Recently, the instrument underwent a process of cross-cultural adaptation to the Brazilian context. The study conducted by Oliveira et al. (2014) proposed a Portuguese version of MedRisk after semantic adequacy (translation, retro translation and specialists panel discussion) and psychometric analysis. The authors evaluated the instrument based on a sample of 303 patients of physiotherapy services inserted in the networks of the SUS and supplementary health in the city of Belo Horizonte (MG). It consists of 13 items (11 specific and 2 global) graduated from 1 to 5 , from "completely disagree" to "completely agree". The average of the values obtained corresponds to the degree of satisfaction ${ }^{(12)}$.

\section{RESULTS}

Table 1 shows the characteristics of the study participants. A total of 46 patients who received physical therapy appointments were recruited.

The statistical description of each individual item and the 2 global measures is shown in Table 2 . 
The rheumatology sector presented a higher mean score (4.75) than the pediatrics sector (4.52), demonstrating that patients' satisfaction is higher. However, in general, values were very close to 5 , indicating a high level of satisfaction in both sectors.

In the rheumatology sector, the item "6- My physiotherapist treated me respectfully", was the one with the highest score (4.90), followed by items 8 "My physiotherapist answered all my questions" and 11 "My physiotherapist provided me with

Table 1 - Characteristics of the participants

\begin{tabular}{ccc}
\hline Variable & Rheumatology Sector & Pediatrics Sector \\
\hline Gender, $\mathrm{n}(\%)$ & & \\
Female & $12(57 \%)$ & $13(52 \%)$ \\
Male & $9(43 \%)$ & $12(48 \%)$ \\
Age (years) & $57.19( \pm 9.68)$ & $5.24( \pm 4.25)$ \\
\hline
\end{tabular}

me detailed instructions on my home exercise program", both with the score of 4.86 .

In pediatrics, item 7 "The clinic employees were respectful" was the one with the highest score (4.80), followed by item 6 "My physiotherapist treated me respectfully" with a score of 4.76, and item 5 "My physiotherapist explained to me carefully the treatments I received" with a score of 4.68 .

The item 3 "The waiting room was comfortable (lighting, temperature, furniture)" was the one with the lowest score in both sectors (4.29 in rheumatology and 4.12 in pediatrics), showing that this was the one that presented the least satisfaction.

Regarding the patients' situation at the time of the evaluation, in both sectors, most users reported feeling "much better" after treatment (57.14\% in rheumatology and 64\% in pediatrics), as described in Table 3.

The individual items ( 1 to 11 ), the age of the patients, the time spent for the patient to go to the clinic and the current

Table 2 - Mean scores of the 13 evaluated items (11 individual and 2 global) by area

\begin{tabular}{|c|c|c|}
\hline Assessed items & Rheumatology & Pediatrics \\
\hline 1- The receptionist was courteous & $4.71 \pm 0.46$ & $4.24 \pm 0.93$ \\
\hline 2- The registration process was adequate & $4.76 \pm 0.44$ & $4.28 \pm 0.84$ \\
\hline 3- The waiting room was comfortable (lighting, temperature, furniture) & $4.29 \pm 1.06$ & $4.12 \pm 1.09$ \\
\hline 4- The opening hours of this clinic were convenient for me & $4.71 \pm 0.56$ & $4.20 \pm 1.00$ \\
\hline 5- My physiotherapist explained to me carefully the treatments I received & $4.81 \pm 0.40$ & $4.68 \pm 0.48$ \\
\hline 6- My physiotherapist treated me respectfully & $4.90 \pm 0.30$ & $4.76 \pm 0.44$ \\
\hline 7- The clinic employees were respectful & $4.81 \pm 0.40$ & $4.80 \pm 0.41$ \\
\hline 8- My physiotherapist answered all my questions & $4.86 \pm 0.36$ & $4.60 \pm 0.58$ \\
\hline 9- My physiotherapist advised me on ways to avoid future problems & $4.52 \pm 0.75$ & $4.48 \pm 0.82$ \\
\hline 10- The clinic and its facilities were clean & $4.81 \pm 0.40$ & $4.52 \pm 0.65$ \\
\hline 11- My physiotherapist provided me with detailed instructions on my home exercise program & $4.86 \pm 0.36$ & $4.44 \pm 0.71$ \\
\hline 12- In general, I am completely satisfied with the services I received from my physiotherapist & $4.86 \pm 0.36$ & $4.76 \pm 0.44$ \\
\hline 13- I would return to this clinic for future services or treatment & $4.86 \pm 0.36$ & $4.84 \pm 0.37$ \\
\hline Overall average & $4.75 \pm 0.53$ & $4.52 \pm 0.74$ \\
\hline
\end{tabular}

Table 3 - Description of the current condition of the patients compared to the previous one to the treatment

\begin{tabular}{|c|c|c|c|c|c|c|}
\hline \multirow{2}{*}{$\begin{array}{l}\text { Current condition } \\
\text { 1- Extremely better }\end{array}$} & \multicolumn{2}{|c|}{ Rheumatology } & \multicolumn{2}{|c|}{ Pediatrics } & \multicolumn{2}{|c|}{ General } \\
\hline & 2 & $9.52 \%$ & 6 & $24.00 \%$ & 8 & $17.39 \%$ \\
\hline 2- Much better & 12 & $57.14 \%$ & 16 & $64.00 \%$ & 28 & $60.87 \%$ \\
\hline 3- A little better & 6 & $28.57 \%$ & 1 & $4.00 \%$ & 7 & $15.22 \%$ \\
\hline 4- A bit better & 1 & $4.76 \%$ & 0 & $0.00 \%$ & 1 & $2.17 \%$ \\
\hline 5-The same & 0 & $0.00 \%$ & 2 & $8.00 \%$ & 2 & $4.35 \%$ \\
\hline 6- A bit worse & 0 & $0.00 \%$ & 0 & $0.00 \%$ & 0 & $0.00 \%$ \\
\hline 7- A little worse & 0 & $0.00 \%$ & 0 & $0.00 \%$ & 0 & $0.00 \%$ \\
\hline 8- Much worse & 0 & $0.00 \%$ & 0 & $0.00 \%$ & 0 & $0.00 \%$ \\
\hline 9- Extremely worse & 0 & $0.00 \%$ & 0 & $0.00 \%$ & 0 & $0.00 \%$ \\
\hline Total Users & 21 & $100 \%$ & 25 & $100 \%$ & 46 & $100 \%$ \\
\hline
\end{tabular}


condition of the patient were crossed with the two global items (12 and 13) to verify which factor influences the most in overall satisfaction. For this, the Spearman coefficient was used. In order to have a significance level of $p<0.05$, the coefficient should be $<-0.35$ or $>0.35$, and the closer the extremes $(-1$ and 1$)$ are, the greater the association between the variables. These data are shown in Table 4.

For the rheumatology sector, the correlation between the specific and global items are the same for the two global variables, that is, the clients' perception of the global variables is the same.

The items Age, Displacement Time and the current state of the patient showed no correlation with the global variables, which indicates that they were not important in the evaluation of personal satisfaction of the service provided. It is important to note that the item "current patient status" presented the lowest correlation with the global variables $(-0.03)$.

The ones with the highest correlations are the variables "8- My physiotherapist answered all my questions" (index 1), "11- My physiotherapist provided me with detailed instructions on my home exercise program" (index 1), "5- My physiotherapist explained to me carefully the treatments I received" (0.84), "7- The clinic employees were respectful" (0.84) and "10- The clinic and its facilities were clean" $(0.84)$.

For the Pediatrics sector, there was a difference between the correlation of the individual items with the two global items. The survey indicates a larger correlation between the individual items and the item " 12 - In general, I am completely satisfied with the services I received from my physiotherapist", having been 9 items correlated, while with item " 13 - I would return to this clinic for future services or treatment", only 6 specific items had a correlation.

With relation to the global item "12- In general, I am completely satisfied with the services I received from my physiotherapist", the individual item that presented higher correlation was "9- My physiotherapist advised me on ways to avoid future problems" (0.71). The items "Age of the patient", "1- The receptionist was courteous", "3- The waiting room was comfortable (lighting, temperature, furniture)" and "Current status of the patient", besides the time of displacement (lower index: -0.36), did not present correlation with this global item.

Referring to the global item " 13 - I would return to this clinic for future services or treatment", the individual item that presented the highest correlation was "7- The clinic employees were respectful" (0.60). The items "age of the patient", "displacement time", "1- The receptionist was courteous", "2- The registration process was adequate", "3- The waiting room was comfortable" (lower index: 0.04), "5-My physiotherapist explained to me carefully the treatments I received", "9- My physiotherapist advised me on ways to avoid future problems "and" current patient status ", did not correlate with this global item.

Table 4 - Description of the correlation between age, displacement time, individual items and current patient status with the two global items, using the Spearman coefficient

\begin{tabular}{|c|c|c|c|c|c|c|}
\hline \multirow[t]{2}{*}{ Assessed items } & \multicolumn{3}{|c|}{$\begin{array}{l}\text { 12- In general, I am completely satisfied } \\
\text { with the services I received from my } \\
\text { physiotherapist }\end{array}$} & \multicolumn{3}{|c|}{$\begin{array}{l}\text { 13- I would return to this clinic for future } \\
\text { services or treatment }\end{array}$} \\
\hline & Rheumatology & Pediatrics & General & Rheumatology & Pediatrics & General \\
\hline Age of the patient & 0.1127 & -0.2164 & 0.0579 & 0.1127 & -0.3438 & -0.0594 \\
\hline Displacement time & -0.1056 & -0.036 & -0.0548 & -0.1056 & -0.2429 & -0.1890 \\
\hline 1- The receptionist was courteous & 0.6456 & 0.1853 & 0.3859 & 0.6456 & -0.0996 & 0.1949 \\
\hline 2- The registration process was adequate & 0.7303 & 0.4018 & 0.5365 & 0.7303 & 0.3121 & 0.4608 \\
\hline $\begin{array}{l}\text { 3- The waiting room was comfortable (lighting, temperature, } \\
\text { furniture) }\end{array}$ & 0.4766 & 0.3001 & 0.3891 & 0.4766 & 0.0499 & 0.2463 \\
\hline 4- The opening hours of this clinic were convenient for me & 0.3781 & 0.4638 & 0.4558 & 0.3781 & 0.4257 & 0.3880 \\
\hline $\begin{array}{l}\text { 5- My physiotherapist explained to me carefully the treatments } \\
\text { I received }\end{array}$ & 0.8416 & 0.4176 & 0.5806 & 0.8416 & 0.1684 & 0.4375 \\
\hline 6- My physiotherapist treated me respectfully & 0.7947 & 0.5614 & 0.6412 & 0.7947 & 0.5212 & 0.6040 \\
\hline 7- The clinic employees were respectful & 0.8416 & 0.6556 & 0.7237 & 0.8416 & 0.6001 & 0.7064 \\
\hline 8- My physiotherapist answered all my questions & 1 & 0.5796 & 0.7137 & 1 & 0.5402 & 0.6897 \\
\hline $\begin{array}{l}\text { 9- My physiotherapist advised me on ways to avoid future } \\
\text { problems }\end{array}$ & 0.4446 & 0.7171 & 0.6020 & 0.4446 & 0.3377 & 0.3865 \\
\hline 10- The clinic and its facilities were clean & 0.8416 & 0.659 & 0.7294 & 0.8416 & 0.5409 & 0.6354 \\
\hline $\begin{array}{l}\text { 11- My physiotherapist provided me with detailed instructions on } \\
\text { my home exercise program }\end{array}$ & 1 & 0.5622 & 0.7041 & 1 & 0.3742 & 0.5741 \\
\hline Current status of the patient compared to before treatment & -0.0379 & -0.2899 & -0.1486 & -0.0379 & -0.2844 & -0.1745 \\
\hline
\end{tabular}




\section{DISCUSSION}

The higher the score found, the greater the satisfaction of the user with the service, with the highest possible value being equal to $5^{(12)}$. Thus, we can say that the degree of satisfaction found in this study was high, with an average of 4.75 for the rheumatology sector and 4.52 for the pediatrics sector. Studies conducted in Belo Horizonte, São Paulo and Maceió in Brazil, as well as in India and Australia, show similar results ${ }^{(8,12,15-17)}$.

A study of satisfaction with physiotherapy assistance in Australia and Korea demonstrated a significant difference in their results, with lower satisfaction of Koreans, which may be due to different tendencies to qualify the service. Asian patients typically have high expectations regarding health services and when these expectations are not met, this may reduce satisfaction with these experiences ${ }^{(18)}$.

The rheumatology sector usually involves older people with chronic diseases. Chronic patients tend to better evaluate the care received and observed that patient satisfaction is directly related to the elements that refer to the patient's interaction with their therapist ${ }^{(2)}$.

On the other hand, those who evaluate the services provided in the pediatrics sector are those responsible for the patients, who are not directly attended by the professionals and usually wait for the children to be attended to. Parents who experience more humanized care, stimulate their participation as an important individual in the treatment of their children, tend to assimilate better how much this can help in the therapeutic progress of the child, demonstrating a greater satisfaction with regard to the place of treatment, to the service and to the professional himself $f^{(19)}$.

Because it is a school clinic, it is possible to assume that trainees provide greater attention, care and kindness in the care of the patient and their relatives. It is believed that in this situation, the trainee clarifies doubts about the illnesses of his patients, explains the procedures to be performed with clarity and uses terms that the patients are able to understand. Supervision by the teacher also ensures patient safety ${ }^{(2)}$.

Second, the service performed is free and patient satisfaction is strongly influenced by factors such as location and cost, regardless of whether the quality is optimal. Patients might be reluctant to disclose negative attitudes towards the health care provider and the environment in which such treatment is offered because of a sense of dependence on care and this fact may lead patients to feel constrained in responding to what they would really like for fear of losing service $^{(3)}$.

The data found in this research are consistent with those found in other studies, demonstrating that the items with the highest satisfaction are related to the therapist-patient interaction and the respect involved in it. And these items showed greater correlation with overall satisfaction ${ }^{(8,12,15,18,20)}$.

Patient's satisfaction is directly related to patient-therapist interaction. Thus, factors such as: clear explanations about treatment, and therapists who demonstrate well-developed communication skills, would be more important for patient satisfaction than the location of the clinic, or quality of available equipment. ${ }^{(15)}$ Some attitudes in the communicative process contribute to greater integration and acceptance, such as the way the professional speaks to the person he is attending, the way to greet him and even the act of making him individualized in the attention. These are forms that facilitate acceptance and reception by representing important interferences in therapeutic outcomes. ${ }^{(6)}$ Thus, the ability of therapists to maintain communication and expose about treatment is among the most important items on the part of users who express their satisfaction with the attributes and attention offered to them, since they feel favored by the treatment received ${ }^{(9)}$.

It was observed that the lower satisfaction is usually related to the physical environment ${ }^{(8,12)}$, but the comfort of the waiting area showed a modest correlation with the measures of global satisfaction ${ }^{(15)}$. However, this provides an important direction when achieving excellence in patient-centered care, since the physical environment emerges as an active and participatory means of caring, developing positive emotional states in relation to treatment expectations. The environment transmits, in the form of small signs, the care policy offered by the institution ${ }^{(6)}$.

Most users of this study reported feeling "much better" after starting treatment, however, this item did not correlate with overall satisfaction ${ }^{(8,18)}$. In this sense, the insertion of a global measure of health status did not show relevance for the measurement of service satisfaction, and in addition, they appear to be distinct constructs ${ }^{(12)}$.

There are several instruments to measure the satisfaction of patients with health services, and some have been built for physiotherapy. The present study showed that the MedRisk instrument is easy to apply and interpret, as well as to promote the graduation of satisfaction and the identification of the specific items that most influence the overall perception of the user satisfaction of physiotherapy services, which is not possible with others instruments developed so far.

Thus, the use of an instrument validated internationally and submitted to cross-cultural adaptation allows the comparison of levels of satisfaction and its components in different social contexts.

\section{CONCLUSION}

We can conclude with this work that the service provided in the clinical-school of physiotherapy of the Centro Universitário do Triangulo was evaluated with a high degree of satisfaction by its users and that items related to the therapist-patient interaction had a greater influence on the overall satisfaction. Thus, demonstrating that the MedRisk instrument is effective, functional and of wide applicability. 


\section{AUTHORS' CONTRIBUTIONS}

All the authors worked actively for the study and participated in all phases. This article is linked to the Doctorate in Dentistry project - FOUFU of the doctor student Élcio Alves Guimarães. Mariana Nunes Faria and Kennedy Rodrigues Lima participated as undergraduate students and made the term paper using this article. Profa MS Kelly D. L. Makhoul guided the term paper of the student. Lucas Resende Sousa was guided in the scientific initiation and participated in the collection of data and preparation of the article. PhD Professors Paulo Cézar Simamoto Jr, Gilmar da Cunha Sousa and Alfredo Júlio Fernandes Neto are counselors of the doctor student Élcio Alves Guimarães. The whole group worked cohesively and dynamically.

\section{CONFLICT OF INTEREST}

The authors declare no conflict of interest.

\section{AUTHOR DETAILS}

2. Physiotherapist, Centro Universitário do Triangulo (Unitri), Uberlândia Minas Gerais - Brazil

3. Physiotherapist, Master Professor of the Centro Universitário do Triangulo (Unitri), Uberlândia - Minas Gerais - Brazil.

4. Physiotherapist, Master student in Health Sciences in the Universidade Federal de Uberlândia (UFU), Uberlândia - Minas Gerais - Brazil.

5. Doctor Professor, Faculty of Odontology, Universidade Federal de Uberlândia (UFU), Uberlândia - Minas Gerais - Brazil.

6. Doctor Professor, Biomedical Sciences Institute, Universidade Federal de Uberlândia (UFU), Uberlândia - Minas Gerais - Brazil.

\section{REFERENCES}

1. FONTES MSV, COLLARES PMC. Satisfação de Usuários no Serviço de Fisioterapia em Clínicas de Fortaleza. Científico. 2014:14(29).

2. SANTOS MB, FERRAZ RRN, DIAS TOS, NERI ASC, OLIVEIRA RS. Satisfação dos Idosos com Relação ao Atendimento Fisioterapeutico Ambulatorial como Instrumento de Gestão em uma Clínica Universitária. Revista de Administração de Roraima. 2014:4(2).

3. SANTOS JB, BICALHO KA, BORGES MBS. Características e nível de satisfação dos pacientes atendidos na clínica-escola de fisioterapia da Universidade Católica de Brasília. EFDeportes.com. 2012:17(171).

4. JUNIOR JFS, ARAÚJO SP, NAVA AV. Serviço prestado em uma clínica escola: fatores influentes na satisfação dos pacientes. Revista Saúde e Pesquisa. 2014:7(1).

5. BALICA SCPR, SILVA IRC, LUZ KPG, SOUZA FCA. Avaliação da satisfação dos pacientes em uma clínica de saúde de fisioterapia de Caxias-MA. Revista Eletrônica Acervo Saúde. 2016:8(2).

6. BRITO TA, JESUS CS, FERNANDES MH. Fatores associados à satisfação dos usuários em serviços de fisioterapia. Rev. Baiana de Saúde Pública. 2012:36(2).
7. VIANA JRS, RAIOCOVITCH T, GOLIAS AG, PETERNELLA FMN, MENDES FCV, GRABOWSKI J. Avaliação da satisfação com a fisioterapia de pacientes atendidos em uma clínica escola de Maringá-PR. Rev UNINGÁ Review. 2014:17(2).

8. HUSH JM, YUNG V, MACKEY M, ADAMS R, WAND BM, NELSON R, et al. Patient satisfaction with musculoskeletal physiotherapy care in Australia: an international comparison. J Man ManipulTher. 2012:20(4).

9. BERNARDINO JCB, et al. Avaliação do nível de satisfação dos pacientes atendidos no núcleo de fisioterapia e reabilitação física de Sobradinho/ DF. Fisioterapia Brasil. 2015:16(1).

10. HALL AM, FERREIRA PH, MAHER CG, LATÍMER J, FERREIRA ML. The influence of the therapist-patient relationship on treatment outcome in Physical Rehabilitation: A Systematic Revew. Phys Ther. 2016: 90(8).

11. SILVA KCC, NUNES RD, ARGEO RF, TAKADA JAP, OLIVEIRA LL, SILVA MP. Nível de satisfação dos pacientes atendidos na Clínica Escola de Fisioterapia do Centro Universitário UNIRG. Revista Amazônia Science \& Health. 2014:2(4).

12. OLIVEIRA NFC, COSTA LOP, NELSON R, MAHER CG, BEATTIE PF, BIE R, et al. Measurement Properties of the Brazilian Portuguese Version of the MedRisk Instrument for Measuring Patient Satisfaction With Physical Therapy Care. Journal of orthopedic \& sports physical therapy. 2014:44(11).

13. BEATTIE PF, PINTO MB, NELSON MK, NELSON R. Patient Satisfaction With Out patient Physical Therapy: Instrument Validation. PhysTher. 2002:82.

14. BEATTIE PF, NELSON RM, LIS A. Spanish-Language Version of the MedRisk Instrument for Measuring Patient Satisfaction With Physical Therapy Care (MRPS): Preliminary Validation. American Physical Therapy Association. 2007:87(6).

15. HINGARAJIA DN. A psychometric analysis of patient satisfaction with physical therapy care. Innovative Journal of Medical and Health Science. 2013: 3(5)

16. CARVALHO VL, CAVALCANTE DM, SANTOS LPD, PEREIRA MD. Satisfação dos pacientes atendidos no estágio curricular de fisioterapia na comunidade. Fisioter Pesq. 2013:20(4).

17. MEDEIROS, FC, COSTA LOP, OLIVEIRA NFC, COSTA LCM. Satisfação de pacientes que recebem cuidados fisioterapêuticos para condições músculoesqueléticas: um estudo transversal. Fisioter Pesq. 2016:23(1).

18. HUSH JM, LEE H, YUNG V, et al. Intercultural comparison of patient satisfaction with physiotherapy care in Australia and Korea: an exploratory factor analysis. J Man Manip Ther. 2013:21.

19. SANTOS EC, RAMOS AS, SOUZA EA. Atendimento pediátrico humanizado, reação da criança e satisfação dos pais no serviço público e privado de fisioterapia respiratória. Estação Científica (UNIFAP). 2011: 1(2).

20. MELO TR, et al. Satisfação dos Usuários de Fisioterapia SUS Paranaguá. Revista UNIANDRADE. 2014:16(2). 